\title{
Alternatives to inpatient treatment in the acute phase Iris Hauth
}

\author{
Address: St. Joseph-Krankenhaus Berlin-Weißensee, Gartenstraße 1, 12088 Berlin, Germany \\ from WPA Thematic Conference. Coercive Treatment in Psychiatry: A Comprehensive Review \\ Dresden, Germany. 6-8 June 2007 \\ Published: 19 December 2007 \\ BMC Psychiatry 2007, 7(Suppl I):SI6 doi:10.1 186/I47I-244X-7-SI-SI6
}

This abstract is available from: http://www.biomedcentral.com/I47I-244X/7/SI/SI6

(c) 2007 Hauth; licensee BioMed Central Ltd.

As a consequence of the enquete report on the status of mental health care in Germany the first community mental health care reform programs were initiated in 1975. In the same period similar large scale activities started in England, the US, Canada and Scandinavia. However, in Germany most of the state mental hospitals were preserved with a reduced number of beds. Community mental health networks are now overall established. Innovative projects like home treatment, assertive community treatment, care management treatment and specialized mental health primary care were not established on a large scale basis across the country. Those more advanced community based services were only developed in several local projects partly funded by a federal program. E.g. the home treatment project in Krefeld including acutely ill patients and the "crisis hotel" project were funded by these means. Furthermore, integrative treatment programs were started by a federal law enabling to build up regional combinations of various primary care and specialized out- and inpatient services and offering a special mechanism of funding (SGB V \$140); this specific option was developed for all medical disciplines (including psychiatry). Most of these projects and programs are accompanied by evaluation and service research due to their model character. Results emerging from the associated research programs will be presented. It is evident that particularly home treatment program increased the satisfication of patients and their relatives by achieving a degree of symptomatic improvement, social integration and rehabilitation which is comparable to hospital based treatment. Furthermore, direct costs are lower than for inpatient treatment. Yet, the number of projects is still limited, and long-term effects and efficiency remains unknown. 